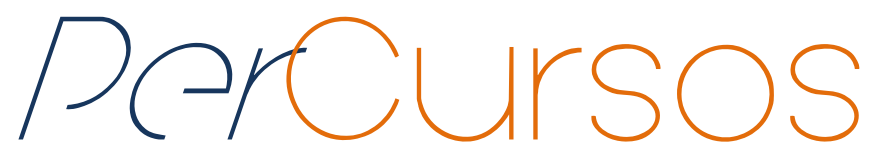

\title{
O ideário da escola cidadã no âmbito das práticas pedagógicas de uma escola pública da periferia de Florianópolis $/ \mathrm{SC}^{1}$
}

\section{Resumo}

Este artigo procura discutir o conceito de cidadania como referência discursiva e argumentativa no interior das formulações políticas no campo educacional, e de como as mesmas são apropriadas pelas famílias e docentes, sobretudo, de uma escola pública e periférica da capital catarinense. Para tanto, delimitamos temporalmente a investigação a partir da aprovação da atual Constituição Federal (1988) até a privatização da escola aqui pesquisada por uma Congregação Marista, ocorrida no final de 2011. Esta escola está localizada num dos territórios do Maciço do Morro da Cruz (Mont Serrat), na área insular da cidade de Florianópolis/SC e, ao longo de um ano e meio, foram realizadas entrevistas e pesquisas bibliográficas e documentais objetivando a compreensão deste conceito polissêmico (cidadania) num território reconhecidamente abandonado pelo Estado e que se escuda por meio de apoio de Organizações Não Governamentais (ONGs).

Palavras-chave: Cidadania; Periferia; Maciço do Morro da Cruz; Escola pública.

\section{Aline Fernandes Carrijo \\ Mestre em História pela}

Universidade Federal do Rio de Janeiro - UFRJ.

$$
\text { Brasil }
$$

aline2586@gmail.com

\section{Jéferson Silveira Dantas}

Doutor em Educação pela

Universidade Federal de Santa

Catarina - UFSC; Professor no

Departamento de Estudos

Especializados em Educação do Centro de Ciências da Educação da Universidade Federal de Santa Catarina - UFSC.

Brasil

jeferson.dantas@ufsc.br

\footnotetext{
${ }^{1}$ Projeto de Pesquisa voltado às políticas públicas para a educação básica e ao atendimento escolar de crianças e jovens pobres dos territórios do maciço do Morro da Cruz. Este projeto conta, atualmente, com o apoio do Grupo de Estudos sobre Política Educacional e Trabalho (GEPETO), núcleo de pesquisa vinculado ao Centro de Ciências da Educação da UFSC, do qual o Professor Doutor Jéferson Silveira Dantas é integrante.
} 


\title{
The ideal of the citizen school as part of teaching practices a public school in the periphery of Florianópolis/SC
}

\begin{abstract}
This article discusses the concept of citizenship as a discursive and argumentative reference within policy formulations in the educational field, and how they are appropriate for families and teachers, especially in a public school and peripheral capital of Santa Catarina. For both temporally delimited research from the approval of the Federal Constitution (1988) to the privatization of school here searched for a Marist Congregation, which occurred in late 2011. This school is located in the territories of the Maciço do Morro da Cruz (Mont Serrat) in the insular area of the city of Florianópolis/SC and over a year and a half, bibliographical and documentary interviews and surveys were conducted aimed at understanding this concept polysemic (citizenship) in a known territory abandoned by the state and which entrenches through support of Non Governmental Organizations (NGOs).
\end{abstract}

Keywords: Citizenship; Periphery; Maciço do Morro da Cruz; Public school.

\section{Para citar este artigo:}

CARRIJO, Aline Fernandes; DANTAS, Jéferson Silveira. O ideário da escola cidadã no âmbito das práticas pedagógicas de uma escola pública da periferia de Florianópolis/SC. Revista PerCursos. Florianópolis, v. 16, n.30, p. 203 - 220. jan./abr. 2015.

\section{DOI: $10.5965 / 1984724616302015203$}

http://dx.doi.org/10.5965/1984724616302015203 


\section{Considerações iniciais}

O campo de pesquisa desta análise é uma escola pública localizada num dos territórios (Mont Serrat) do Maciço do Morro da Cruz, uma cadeia montanhosa irregular situada na área insular da cidade de Florianópolis/SC onde habitam, praticamente, 30 mil pessoas, divididas em pelo menos 20 territórios e com todas as precariedades estruturais possíveis (DANTAS, 2013). Sua ocupação desordenada é fruto de um processo de modernização na capital catarinense, ocorrida nas primeiras décadas do século XX, o que gerou a expulsão de pobres, afrodescendentes, migrantes e trabalhadores da construção civil das áreas centrais da cidade para as encostas dos morros.

Esta escola foi oficialmente inaugurada em 1978 e, até 2011, era de responsabilidade do poder público estadual, que repassou o prédio e todo o seu mobiliário por um período de dez anos para uma Congregação Marista - Rede Marista de Solidariedade -, esta última, com grande atuação comunitária no território do Mont Serrat. Longe de ser uma questão menor em nossa análise, o fato dos governos catarinenses, nos últimos dez anos, sobretudo, desresponsabilizarem-se com a questão pública a ponto de favorecerem uma congregação de caráter privado ${ }^{2}$, sugere que o sucateamento de escolas públicas localizadas, especialmente, nas periferias, é uma ação deliberada destas alianças político-partidárias ${ }^{3}$.

Antes de seu processo de privatização ou de terceirização, observamos que $98 \%$ das crianças e jovens que estudavam na escola residiam nos territórios do Mont Serrat ou Alto da Caieira - este último, situado acima do Mont Serrat - portanto, um território mais íngreme e de ocupação recente. É visível a ausência de saneamento básico e/ou canalização do esgoto doméstico, além da insegurança habitacional, já que boa parte das casas é construída nas encostas dos morros, correndo sérios riscos de deslizamento, notadamente nos dias de intensa precipitação pluviométrica.

\footnotetext{
${ }^{2}$ Esta Congregação não cobra mensalidades dos/as estudantes atendidos/as (praticamente, todos residentes dos territórios do Mont Serrat e Alto da Caieira). Contudo, o caráter laico da instituição já não existe mais e a proposta pedagógica da escola não corresponde ao que foi discutido no Projeto Político-Pedagógico (PPP) antes de seu processo de privatização/terceirização.

${ }^{3}$ Os governos de Luiz Henrique da Silveira (2003-2010) e de João Raimundo Colombo (2011-2014) foram resultados de uma forte aliança partidária, reunindo o PMDB, PSDB e o DEM.
} 
Nesta direção, como assegurar uma escola cidadã para populações que não têm assegurados direitos mínimos de cidadania? Ou ainda: como os professores e professoras lidavam com a situação de precarização material das crianças e familiares atendidos pela escola, antes de seu processo de privatização?

Tais problematizações acima elencadas vêm acompanhadas da retórica discursiva da expressão "cidadania", adotada ad nauseam como panaceia para os problemas educacionais e incorporadas nos documentos oficiais voltados à formação de professores, reorganização curricular, etc., principalmente a partir da década de 1990. Logo, definimos como recorte temporal o período que se estende de 1988 (promulgação da atual Constituição Federal) até 2011, ano em que a escola foi entregue à Congregação Marista pelo poder público estadual.

Entendemos ainda que a concepção de "educação para todos" omite ou oculta a ideia de que em nosso país, devido à imensa desigualdade social e concentração de renda, há a persistência nefasta do "dualismo educacional”, i.e., uma escola de qualidade socialmente referendada voltada para as classes dirigentes e uma escola para as classes populares, via de regra sucateada infraestruturalmente e com imensos problemas formacionais. Para a educadora Lílian do Valle (2001), a formação ética dos futuros cidadãos é o principal sentido atribuído à ação educativa, mas como isto se configura num modelo formacional que a priori já se apresenta como dual e profundamente desigual? É o que procuraremos ventilar neste artigo.

\section{Cidadania e educação em suas 'linhas' e 'entrelinhas'}

No segundo semestre de 2008, a escola aqui analisada desenvolveu um projeto denominado Pacto de Convivência, baseado nas formulações de Milani (2004), doutor em saúde pública pela Universidade Federal da Bahia (UFBA) e encampado por uma professora da área de Ciências da referida escola. Milani criou uma cartilha com proposições de boa convivência entre estudantes e professores por meio do Instituto Nacional de Educação para a Paz (INPAZ). A professora de Ciências implementou o projeto, inicialmente, de forma isolada (apenas em suas turmas) e, posteriormente 
sugeriu que o "pacto" fosse ampliado para toda a escola. Embora bem intencionado, percebe-se que tal "pacto" partia do pressuposto de que o exercício da cidadania deveria ficar restrito a um amoldamento de práticas comportamentais abrangentes ou genéricas, já que as crianças e jovens dos territórios do Mont Serrat e Alto da Caieira não traziam de seu âmbito familiar tais "habilidades" de boa convivência e cordialidade. Pode-se dizer, em outras palavras, que as ações educativas nesta escola, ainda que carregassem a flâmula de cidadãs, estavam encharcadas de prescrições moralizadoras e não de ações efetivamente mobilizadoras, que em última análise são as que podem transformar, conceitualmente, determinadas práticas pedagógicas.

A escola em tela fez parte da Comissão de Educação do Fórum do Maciço do Morro da Cruz (CE/FMMC), uma comissão de escolas públicas que atendiam, basicamente, crianças e jovens dos territórios do Maciço do Morro da Cruz (DANTAS, 2013). Tal comissão de escolas se articulou em 2000, deixando de existir a partir de 2012. Em síntese, a CE/FMMC lutava por melhores condições de trabalho dos professores nas escolas, eleição direta para diretores, formação continuada em serviço autônoma e dirigida às demandas específicas das unidades de ensino, merenda escolar sem agrotóxico, diminuição da evasão escolar, mudanças nos processos de avaliação da aprendizagem, problematização sobre a incidência do narcotráfico em determinados territórios do Maciço do Morro da Cruz, etc. Mesmo com o acúmulo histórico desta significativa experiência política e pedagógica da Comissão de Educação, os problemas estruturais da escola (ausências sistemáticas dos professores, equipe de coordenação pedagógica incompleta, elevadas taxas de evasão e reprovação, etc.), não conseguiram ser dirimidos, apesar do protagonismo da unidade de ensino do Mont Serrat na articulação da Comissão de Educação. Em 2007, de acordo com dados fornecidos pela própria escola, a taxa média de abandono foi de $8 \%$, chegando a $19 \%$ na primeira série do ensino fundamental. Considerando os oito anos do ensino fundamental ${ }^{4}$, a taxa média de reprovação foi de $21 \%$, sendo que $23 \%$ dos/as estudantes encontravam-se em séries atrasadas em relação à idade (distorção série/idade).

\footnotetext{
${ }^{4}$ Já que neste período a escola ainda estava organizada por séries e não por anos, conforme preconiza a Lei 11.274/2006, que instituiu o ensino de nove anos no ensino fundamental em todo o Brasil.
} 
No que tange às concepções curriculares oficiais (Diretrizes Curriculares Nacionais, Parâmetros Curriculares Nacionais, Proposta Curricular de Santa Catarina) e outras orientações de sistematização do conhecimento nos processos de escolarização, entendemos que as mesmas constituem um importante legado documental para se empreender a interpretação do conceito de "cidadania”. Ressalvamos, contudo, que esta discussão não era muito presente na escola, tendo como expressão um Projeto PolíticoPedagógico defasado e pouco articulado às dinâmicas educativas vivenciadas pela unidade de ensino.

No final de 2008, foi criada na escola uma turma de Educação de Jovens e Adultos (EJA) no período noturno e 134 crianças passaram a ficar três horas a mais na unidade de ensino, por apresentarem baixos índices de rendimento escolar. Isto se deveu, principalmente, pelo fato de a escola ter ficado entre as que apresentaram piores notas no Índice de Desenvolvimento da Educação Básica (IDEB) na Grande Florianópolis. Logo, a mesma passou a integrar o programa Mais Educação, instituído em 2007 pelo Ministério da Educação (MEC). Na prática, em nível nacional, programas como o Mais Educação, tornaram-se o carro-chefe de uma perspectiva de formação em tempo integral que procura fortalecer a formação cultural de crianças e jovens e aproximar as escolas das famílias, associando suas mudanças curriculares ao PPP da escola.

Se, por um lado, o aumento do tempo na escola pode significar um "aprofundamento de experiências cotidianas compartilhadas e o enriquecimento da vida intra-escolar e a estabilidade de seus quadros profissionais" (CAVALIERE, 2009, p. 58), não podemos perder de vista que tal atendimento aos estudantes, especialmente das classes populares, não pode se transformar em mero "atendimento, com sentido limitadamente assistencialista, ou em mero 'consumo', isto é, ocupação com atividades desconectadas de um PPP, organizados como uma espécie de mercado" (CAVALIERE, 2009, p. 58). Nessa direção, o programa Mais Educação tem se mostrado inepto diante das imensas demandas das escolas públicas, já que ao não privilegiar a contratação de profissionais habilitados e não remunerá-los de forma digna, acaba por reduzir sua ação a uma série de atividades pedagógicas duvidosas do ponto de vista da apropriação dos conhecimentos científicos produzidos pela humanidade. Este, talvez, seja um dos piores 
exemplos de modelo de “educação integral” em voga nos processos de escolarização no Brasil, até o momento.

Destarte, a escola localizada no território do Mont Serrat foi a primeira a adotar o programa Mais Educação em Florianópolis, com um aporte de recursos do MEC na ordem de $\operatorname{R}$ 40.000,00 para materiais de consumo, alimentação e ajuda de custo para os/as professores/as envolvidos/as. As aulas "extras" no contraturno foram organizadas para as áreas de matemática, letramento, capoeira, informática, teatro e diversidade étnicoracial, escolhidas - segundo a direção da escola na época - de acordo com a realidade das crianças e jovens daquele território do Maciço do Morro da Cruz. Cabe ressaltar, como importante dado de pesquisa, que na escola 92\% das 300 crianças matriculadas eram negras.

Pode-se dizer que desde a redemocratização do Brasil em meados da década de 1980 e da aclamação da atual Constituição Federal (conhecida como a Constituição “cidadã”), as proposições curriculares em nível nacional e regional ressignificaram, prescritivamente, a atuação dos sujeitos históricos nos espaços educativos, tendo em vista a reacomodação dos movimentos sociais e das teorias pedagógicas. Em outras palavras, se durante o regime militar (1964-1985) as forças sociais em luta estavam mais polarizadas, nos dias de hoje elas estão mais pulverizadas, denotando diferentes formas/estratégias de consenso, especialmente no campo educacional.

Fonseca (2006) no artigo intitulado "Exaltar a pátria ou formar o cidadão" expressa com clareza como as elites econômicas em diferentes períodos históricos fazem determinadas exigências modernizantes (na qualificação da força de trabalho propriamente dita e na escola), estabelecendo a todo o momento pactos consensuais com os setores produtivos mais amplos da sociedade brasileira. O pensamento liberal entende que a formação do cidadão produtivo precisa corresponder à obediência às leis instituídas, mesmo que este cidadão seja impedido de exercer plenamente os seus direitos sociais e políticos. Não por acaso, ao se projetar um ideário curricular escolarizado em nível nacional, projeta-se também uma ideia de cidadania. 
Já Faria Filho (2000, p. 137), exemplifica que a escola brasileira de primeiras letras ainda no século XIX, procurava generalizar a educação para a população, divisando na instrução primária uma importante ação estratégia civilizatória do povo brasileiro. Buscava-se, assim constituir condições viáveis de governabilidade ou a existência de um Estado independente com capacidade de governar.

Ora, os documentos oficiais, como são os casos das proposições curriculares e legislações educacionais, expressam determinações históricas que estão espalhadas em diferentes partes deste corpus documental. Mas a fonte documental em si não nos diz nada, a menos que façamos as perguntas adequadas às evidências, o que exige uma interpretação de largo alcance ou uma decupagem da fonte, revelando/desvelando a dinâmica da vida social.

Para a historiadora Kátia Abud, geralmente, os textos oficiais são pensados para uma escola e para um estudante ideal. Estão ausentes destes documentos as rupturas e as resistências ativas dos sujeitos históricos, denotando a relativização da realidade e um elevado conformismo epistemológico.

Os currículos e programas de escolas públicas, sob qualquer forma que se apresentem (guias, propostas, parâmetros), são produzidos por órgãos oficiais que os deixam marcados com suas tintas, por mais que os documentos pretendam representar o conjunto dos professores e os 'interesses dos alunos'. E por mais que tais grupos reivindiquem participação na elaboração de instrumentos de trabalho, ela tem se restringido a leituras e discussões posteriores à sua elaboração [...]. Mesmo assim, representam uma forma de produção de conhecimento que será acessível à maior parte da população escolarizada no nível fundamental. (ABUD, 2006, p. 28)

O PPP da escola aqui estudada é resultado deste pouco interesse em se pensar, efetivamente, uma concepção de escola e de educação, já que as suas diretrizes foram pensadas por setores da escola e não pelo seu coletivo (professores, estudantes e familiares). Apesar disso, os professores entrevistados para esta investigação foram, praticamente, unânimes em relatar que o PPP é um importante instrumento de diagnóstico da realidade escolar e da comunidade atendida. 
Por outro lado, os repetidos episódios de agressão verbal aos professores da escola por parte dos estudantes e uma sensação de impotência ou mesmo de frustração dos docentes, que se viam, a cada dia, mais esgotados fisicamente e psiquicamente, revelam também o quanto a expressão guarda-chuva “cidadania" é restritiva e desconectada de realidades tão brutais como essa que apresentamos aqui. Há ainda uma profunda internalização individual do fracasso por parte dos professores, que não conseguem mais se enxergar como classe, como coletivo, e acabam se culpando por algo que não funciona em sua prática pedagógica, ainda que os limites infraestruturais e pedagógicos estejam assentados desde o princípio.

Para Inês Barbosa de Oliveira, a prática pedagógica é diretamente influenciada por fatores presentes na complexidade do cotidiano escolar: “[...], os professores tecem suas práticas cotidianas a partir de redes, muitas vezes contraditórias, de convicções e crenças, de possibilidades e limites, de regulação e emancipação" (2005, p. 36). Ou seja, as práticas pedagógicas dos professores vivenciadas numa determinada cultura escolar dependem de uma série de elementos, tais como as condições estruturais das escolas, a história de vida dos professores e suas concepções de mundo, o capital econômico e cultural das crianças e familiares, o tempo de trabalho numa escola, etc.

Fica-nos nítido que a experiência profissional de cada professor de algum modo influencia sua prática pedagógica. Ivor Goodson (1999) relata que além da importância em se estudar as propostas curriculares oficiais, é necessário que se analise a "realização do currículo" em sala de aula. Para este autor, isto pode ser concretizado por meio da história de vida dos professores. Consideramos então aqui a necessidade de se realizar uma conexão/articulação entre os estudos de situações e vivências escolares com a dimensão biográfica e histórica dos docentes.

A definição ou a compreensão de cidadania, portanto, remetida a este contexto histórico, é tributária das ideias iluministas e, por isso, segue o princípio da universalidade, o que é inviável numa sociedade de classes. Para o historiador José Murilo de Carvalho, das três dimensões de cidadania (civil, política e social), algumas podem estar presentes e outras não, conforme sua interpretação: 
[...] houve no Brasil pelo menos duas diferenças importantes. A primeira refere-se à maior ênfase em um dos direitos, o social, em relação aos outros. A segunda refere-se à alteração na sequência em que os direitos foram adquiridos: entre nós o social precedeu os outros. [Portanto] quando falamos de um cidadão inglês ou norte-americano, e de um cidadão brasileiro, não estamos falando exatamente da mesma coisa. (CARVALHO, 2008, p. 11)

Inês Barbosa de Oliveira (2005) considera que é praticamente impossível se imaginar um único conceito ou padrão de cidadania, já que o mesmo foi cunhado num contexto histórico de emergência da burguesia na Europa e, portanto, não pode servir como referência para outras nações do mundo. A atual concepção de cidadania estaria servindo tanto para incluir como para excluir determinados segmentos da sociedade brasileira. Assim, faz-se necessário analisar como a compreensão de cidadania é ensinada e entendida nos documentos oficiais e como é sistematizada nos bancos escolares. Tal conceito ou terminologia, não nos esqueçamos, atende à reestruturação do processo produtivo capitalista na contemporaneidade; logo, ser cidadão significa ter capacidade de consumo ou um bom poder aquisitivo, o que confronta brutalmente com as condições de existência dos moradores dos territórios do Maciço do Morro da Cruz.

Para finalizar esta seção, atentamos ainda para um aspecto essencial: o de que os professores e professoras, por pertencerem a uma mesma categoria de trabalho e lidarem com situações semelhantes relacionadas ao seu métier, apresentam as condições concretas para também modificarem suas práticas pedagógicas. Os professores não representam um amontoado de indivíduos, mas um conjunto de trabalhadores e trabalhadoras que exibem padrões relacionais, formulando ideias e operando resistências nestes ambientes institucionalizados. Afinal, como nos ensina E.P. Thompson (1997), a classe social é definida pelos seres humanos enquanto vivem a sua própria história. E com os professores isto não é diferente! 


\section{Para além dos muros: cidadania e educação no território do Mont Serrat}

As obras do Programa de Aceleração do Crescimento (PAC) do governo federal tiveram início no Maciço do Morro da Cruz em março de 2008. Tal programa tinha como previsão de investimento em infraestrutura em todo o território nacional a quantia de $\mathrm{R} \$$ 503,9 bilhões. Isto incluiria projetos de saneamento básico, habitação, transporte urbano, energia elétrica e recursos hídricos.

Contudo, as obras do PAC no Maciço do Morro da Cruz até hoje não foram efetivamente concluídas, tendo em vista atrasos no cronograma das obras, novas licitações, etc. Uma das lideranças do Mont Serrat e que, inclusive, foi secretário do Fórum do Maciço do Morro da Cruz, relata que em 2007 teriam ocorrido cinco reuniões para discutir o Plano Diretor de Florianópolis. Tais encontros estavam centralizados nas "leituras comunitárias", mas que foram simplesmente desmobilizadas por conta das obras do PAC. Em outras palavras, o denominado Plano Diretor Participativo (PDP) deixou de ser debatido nos territórios do Maciço, denotando um contrassenso em relação às demandas específicas de tais territórios.

Para Claudia Castellanos Pfeiffer (2001), em seu artigo intitulado “Cidade e sujeito escolarizado", há uma concepção nos textos urbanísticos desde o século XIX de pressupor uma cidade já pronta e um sujeito já pronto para ocupá-la. Nesta direção, constrói-se a ideia de um sujeito e de uma cidade homogêneos, completos e estabilizados, havendo aí um silenciamento do "real da cidade". As favelas ou morros são apresentados como uma antítese da cidade; o lugar ou o território da violência e da sujeira; aquilo que a cidade não deve ser. É o que Pfeiffer denomina de "territorialização dos problemas da cidade", aliado à fabricação do medo por meio da mídia tradicional/conservadora e às políticas de tolerância zero, contribuindo para a estigmatização ou guetização dos territórios periféricos.

Fica patente que há enormes desigualdades de acesso a bens culturais e sociais na cidade de Florianópolis. Para a antropóloga Alba Zaluar (2004), chama a atenção o caráter dúbio do Estado, que numa mão reprime e na outra defende direitos políticos e sociais. 
Contudo, segundo esta autora, não se podem ignorar determinados aspectos positivos da cidadania realizados por meio do Estado:

A própria ideia dos direitos de minorias é universalista e não tem sentido senão num contexto cultural e institucional em que os demais direitos, inclusive o direito à vida e à liberdade de expressão, sejam vigentes. Trata-se de um universalismo com um centro único de ideias substantivas. O direito à diferença passa, pois, pelo discurso individualizante, a um só tempo universal e particular, da cidadania. (ZALUAR, 2004, p. 19)

No território do Mont Serrat, todavia, a compreensão de cidadania se confunde com as relações associadas à família, já que a mesma é a referência principal para aqueles que não valorizam os estudos ou a formação escolarizada. No entanto, isto não significa que as relações familiares da classe trabalhadora sejam tranquilas ou estruturadas de acordo com os padrões típicos de uma família burguesa nuclear, e mesmo as famílias burguesas não se estruturam mais como há décadas atrás. Contudo, o que a nossa investigação descobriu é que as famílias estruturadas há mais tempo nos territórios dos morros discordam enfaticamente dos modos de vida dos moradores recentes, vistos com desconfiança e não raramente isolados de determinadas festas e confraternizações comunitárias, sobretudo, aquelas de caráter religioso. Em outras palavras, embora o conceito de "cidadania" para os moradores do Mont Serrat se encontre conexo ao conceito de família, o que acaba sobressaindo em tais discussões é o "código de conduta" no interior deste território.

O conceito de cidadania parece, também, estar diretamente ligado a essa relação dos indivíduos com a sociedade ou o Estado. Logo, a família muitas vezes está imersa num conceito maior, a denominada "família ampliada", como menciona Norbert Elias em a Sociedade dos indivíduos (1994). As evidências apontaram desta maneira que para a pequena amostragem de familiares entrevistados e que têm filhos na escola aqui investigada, a concepção de cidadania está dividida entre aqueles que percebem em tal conceito a garantia dos direitos políticos, sociais e econômicos e para aqueles que observam mais os aspectos da convivência social. 
Para os professores da escola, a ausência da família no acompanhamento do rendimento escolar de seus filhos é um fator extremamente importante. A falta de incentivo dos pais parece ser uma reclamação não apenas desta escola, mas de grande parte das unidades de ensino do Brasil. No dia 17 de outubro de 2008 foi lançado o relatório "A qualidade da educação sob o olhar dos professores", da Fundação SM e da Organização dos Estados Ibero-Americanos (FUNDAÇÃO SM/OEI, 2008). Foram entrevistados 8.773 docentes de 15 unidades federativas do país. De acordo com o relatório ${ }^{5}$, quase a totalidade dos docentes acredita que a família delega suas responsabilidades à escola em excesso. Ou seja, tornou-se lugar-comum nas escolas públicas brasileiras reconhecer que as famílias são desestruturadas e que os professores precisam arcar com mais obrigações do que deveriam.

Conflitos geracionais no território do Mont Serrat são comuns. Moradores mais antigos chegam a expressar que o Estado deveria ser mais duro e rígido com os pais que não educam direito os seus filhos. Mas, quando se depura melhor quem deve zelar pela boa conduta dos filhos, esta responsabilidade recai sobre as mulheres, muitas vezes abandonadas pelos maridos e vivendo às expensas de familiares ou amigos. 0 conservadorismo de tais opiniões expressa também determinados padrões e valores de conduta arraigados, que se desestabilizam com a presença de novos sujeitos e arranjos familiares em tais territórios.

Identificamos ainda nas manifestações artísticas, como é o caso do rap, os desejos de consumo dos jovens que vivem nestes territórios periféricos, ainda que para esse intento precisem fazer parte de facções criminosas ligadas ao narcotráfico. Como bem assinalou o historiador Nicolau Sevcenko (2001), a ganância se tornou um bem ou uma herança positiva. Os valores da sociedade capitalista são compartilhados tanto pela burguesia quanto pela classe trabalhadora, tanto por aqueles que moram no "centro" quanto para aqueles que moram nas "periferias". Em síntese, a participação no mercado (como consumidor, sobretudo) é uma forma de cidadania, totalmente avessa à participação na vida da pólis.

\footnotetext{
5 Trata-se de um relatório não governamental, realizado por uma instituição espanhola e apoiada pelo controverso movimento Todos pela Educação, tendo como consultora a professora Maria Malta Campos, da Fundação Carlos Chagas.
} 
Não poderíamos encerrar esta seção sem chamar a atenção para a presença das Organizações Não Governamentais (ONGs) nos territórios do Maciço do Morro da Cruz e, especialmente, no Mont Serrat. Grande parte das crianças frequentam oficinas realizadas pela ONG Escrava Anastácia. Hoje, com a privatização da escola pela mesma congregação que está à frente da ONG Escrava Anastácia, as crianças não precisam mais fazer atividades de reforço no contraturno. Se, por um lado, não podemos ignorar a importância destas ONGs no Mont Serrat, temos total clareza de que precisamos problematizar a proliferação de ONGs em territórios periféricos de várias cidades do Brasil, o que diminui a responsabilidade direta do Estado e esvazia a participação política das camadas populares.

\section{Considerações finais}

Procuramos de forma breve estabelecer um diálogo com o território do Mont Serrat e com a escola pública que ali se situava tendo como leitmotiv a fustigada expressão "cidadania", sem deixar de lado questões macros, da qual a cidade como um todo se relaciona. Afinal, a escola está necessariamente dentro da cidade e quem está na escola acessa a cidade (ainda que de forma desigual/residual em contraponto a outras classes sociais). Como bem assinala Maria Stella Bresciani na obra "Cidade, cidadania e imaginário" (2001, p. 13), "A rígida divisão do tempo imposta pelas atividades do citadino, pontualidade e fragmentação interligadas aos esquemas mais amplos de organização do trabalho e do lazer, tem como ponto de referência uma 'gramática da vida urbana"”.

Todavia, a cidade nem sempre é planejada para tornar os seus sujeitos mais seguros e felizes. A construção da cidade segue determinados interesses privados, como enuncia Eni Orlandi (2004, p. 151):

[...] há uma sobreposição do urbano sobre a cidade, resultando daí que não há espaço "vazio" desse ponto de vista. Não há lugar para a falta, para o possível. Os sentidos do "público" já estão desde sempre saturados, preenchidos pelo urbano. A cidade é impedida de significar em seus não sentidos, não dando visibilidade a outras formas de relações sociais. Os sentidos da cidade não são capazes de dizer o movimento do 
social. Daí resultam a violência, a ilegalidade, o impróprio, ditos pelos préconceitos: o racismo, a exclusão, a marginalidade, o imaginário da oposição hierarquizada entre rural e urbano, diferenças remetidas à tecnologia e à ciência onde o urbano está do lado do científico, do tecnologicamente desenvolvido, da mídia, etc., sendo a escola o lugar em que essas divisões fazem seu sentido.

Queremos esclarecer assim, de forma enfática, que as crianças, jovens e familiares (sujeitos desta investigação) de um dos territórios do Maciço do Morro da Cruz são, por conseguinte, sujeitos que formalmente têm garantidos a cidadania civil e a cidadania política, o mesmo não ocorrendo em relação à cidadania social. Em outras palavras,

A extensão e a qualidade do acesso aos direitos correspondentes, pela população, no Estado capitalista, depende da particular forma de gestão deste, isto é, da forma específica pela qual é resolvida a contradição entre as exigências do capital no sentido de viabilização da acumulação e as reivindicações da população, em termos de políticas sociais, necessárias à satisfação das necessidades essenciais admitidas como direito de todos e condição para a minimização dos conflitos entre capital e trabalho. (LOPES; SILVA; MALFITANO, 2006, p. 115)

Para Cury (2008, p. 214-215), com o qual concordamos, a face da desigualdade social é muito mais severa e perversa para a classe trabalhadora e os seus filhos, já que estes continuam submetidos de forma clientelística nos diferentes espaços da vida produtiva e escolar. Situações de desigualdade e de discriminação produzidos fora da escola também reforçam situações de precariedade no interior dela (CURY, 2008, p. 217). Logo, como tratar de cidadania se há em nosso país desigualdades escolares que expressam um verdadeiro "crime de abandono intelectual" por parte do Estado? Ou ainda nos termos de Maria Helena Michels (2006), o discurso da "escola cidadã" associado ao discurso da "escola inclusiva", contraditoriamente, quanto mais "inclui" mais "exclui", pois as condições materiais e pedagógicas de aprendizagem não são devidamente garantidas pelo aparato estatal.

Portanto, a nossa contribuição para este debate se dá no sentido de se reconhecer as falas e vozes silenciadas das camadas populares ou da classe trabalhadora. Já na década de 1960, o historiador E. P. Thompson, ao publicar o artigo intitulado The History 
from Below, trazia à baila as histórias vistas de baixo, incorporando as mesmas nos jargões dos historiadores sociais. E se levarmos em consideração a ideia de circularidade cultural de Ginsburg (2002), poderemos entender com maior profundidade e rigor os processos de troca cultural nos territórios do Maciço do Morro da Cruz, que acontecem tanto vertical como horizontalmente e de forma intensa, por mais que haja divisas e conceitos ou opiniões estereotipadas sobre determinados temas. E isso é claramente percebido na problematização de um conceito tão controverso como é o de “cidadania".

\section{Referências}

ABUD, Kátia. Currículos de História e políticas públicas: os programas de História do Brasil na escola secundária. In: BITTENCOURT, Circe Maria Fernandes; ALMEIDA, Adriana Mortara. $O$ saber histórico na sala de aula. 11 ed. São Paulo: Contexto, 2006.

BRESCIANI, Maria Stella; NAXARA, Márcia (Orgs.). Memória e (res)sentimento. Campinas/SP: UNICAMP, 2001.

CAVALIERE, Ana Maria. Escolas de tempo integral versus alunos em tempo integral. Em Aberto, v. 22, n. 80, p. 51-63, abr. 2009.

CARVALHO, José Murilo de. Cidadania no Brasil: o longo caminho. 10 ed. Rio de Janeiro: Civilização Brasileira, 2008.

CURY, Carlos Roberto Jamil. A educação escolar, a exclusão e seus destinatários. Educação em Revista, Belo Horizonte, n. 48, p. 205-222, dez. 2008.

DANTAS, Jéferson. Reescrever o mundo com lápis e não com armas: a experiência política e pedagógica da Comissão de Educação do Fórum do Maciço do Morro da Cruz em Florianópolis/SC. Florianópolis: Editoria em Debate, 2013.

ELIAS, Norbert. A sociedade dos indivíduos. Rio de Janeiro: Zahar, 1994.

FARIA FILHO, Luciano Mendes de. Instrução elementar no século XIX. In: LOPES, Elaine et. al. (Orgs.). 500 anos de Educação no Brasil. Belo Horizonte: Autêntica, 2000. 
FONSECA, Thais Nívia de Lima e. História \& ensino de história. Belo Horizonte: Autêntica, 2006.

FUNDAÇÃO SM/OEI. A qualidade da educação sob o olhar dos professores. 2008.

Disponível em: < http://www.todospelaeducacao.org.br//arquivos/biblioteca/25812d57706e-45fb-8ed3-93ca6fce8178.pdf.> Acesso em: 6 out. 2014.

GINSBURG, Carlo. 0 queijo e os vermes: o cotidiano e as ideias de um moleiro perseguido pela Inquisição. 3 ed. São Paulo: Cia das Letras, 2002.

GOODSON, Ivor. Currículo: teoria e história. 3 ed. Petrópolis/RJ: Vozes, 1999.

LOPES, Roseli Esquerdo; SILVA, Carla Regina; MALFITANO, Ana Paula Serrata.

Adolescência e juventude de grupos populares urbanos no Brasil e as políticas públicas: apontamentos históricos. Revista HISTEDBR [on-line], Campinas/SP, n. 23, p. 114-130, set. 2006. Disponível em: http://www.histedbr.fe.unicamp.br/revista/edicoes/23/arto8_23.pdf. Acesso em: 24 out. 2014.

MICHELS, Maria Helena. Gestão, formação docente e inclusão: eixos da reforma educacional brasileira que atribuem contornos à organização escolar. Revista Brasileira de Educação, v. 11, n. 33, set./dez. 2006.

MILANI, Feizi Masrour. Tá combinado! construindo um pacto de convivência na escola. Salvador: Ed. INPAZ, 2004.

OLIVEIRA, Inês Barbosa de. Currículos praticados: entre a regulação e a emancipação. 2 ed. Rio de Janeiro: DP\&A, 2005.

ORLANDI, Eni P. Cidade dos sentidos. Campinas: Pontes, 2004.

PFEIFFER, Claudia Castellanos. Cidade e sujeito escolarizado. In: ORLANDI, Eni P. Cidade atravessada: os sentidos públicos no espaço urbano. Campinas: Pontes, 2001.

SEVCENKO, Nicolau. Aceleração tecnológica, mudanças econômicas e desequilíbrios. In: SEVCENKO, Nicolau. A corrida para o século XXI: no loop da montanha-russa. São Paulo: Cia das Letras, 2001.

THOMPSON, E.P. A Formação da classe operária inglesa. 3 Ed. Rio de Janeiro: Paz e Terra, 1997.

VALLE, Lílian do. Ainda sobre a formação do cidadão: é possível ensinar a ética? Educação e Sociedade, ano XXII, n. 76, out. 2001. 
ZALUAR, Alba. Integração perversa: pobreza e tráfico de drogas. Rio e Janeiro: Ed. da FGV, 2004 .

Recebido em: 06/10/2014 